\title{
Capacidade estatal e eficácia na política de atenção a crianças e adolescentes
}

\author{
Geralda Luiza de Miranda \\ Universidade Federal de Minas Gerais (UFMG) \\ Valéria Cristina de Oliveira \\ Universidade Federal de Minas Gerais (UFMG)
}

O artigo analisa a eficácia do serviço de acolhimento institucional para crianças e adolescentes em situação de risco na realização das metas de excepcionalidade e provisoriedade da medida, preconizadas pelo ECA. O argumento é o de que essa eficácia relaciona-se com a capacidade das burocracias, derivada de seu arranjo institucional. A análise sustenta-se na discussão teórica desse arranjo, no mapeamento de sua tradução operacional e na avaliação da configuração do provimento do serviço. Os dados que subsidiam a análise são os do Censo Suas, complementados por informações coletadas em um estudo de caso. Verifica-se que, em perspectiva histórica, o acolhimento institucional se tornou uma medida bem menos recorrente, mas ainda não é excepcional, e que a provisoriedade está relacionada com a natureza, localização e tempo de implantação das unidades, com a capacidade e configuração das burocracias e com o perfil das crianças e adolescentes.

Palavras-chave: assistência social, política social, capacidade estatal, eficácia, burocracia

[Artigo recebido em 8 de fevereiro de 2017. Aprovado em 21 de julho de 2017.] 


\section{Capacidad estatal y eficacia en la política de atención a niños y adolescentes}

En este trabajo se analiza la eficacia del servicio de atención institucional para niños y adolescentes en situación de riesgo en la consecución de los objetivos recomendados por el ECA: excepcionalidad y temporalidad de la medida. El argumento es que esta eficacia se relaciona con la capacidad de las burocracias, derivada de su arreglo institucional. El análisis se basa en la discusión teórica de esta disposición, el mapeo de la traducción operativa y la evaluación de la disposición de la configuración de servicio. Los datos que apoyan el análisis son el Censo Suas, complementados con información recogida en un estudio de caso. Se ha encontrado que, en una perspectiva histórica, la atención institucional se ha convertido en una medida mucho menos recurrente, pero no es excepcional, y que la temporalidad se relaciona con la naturaleza, ubicación y data de creación de las unidades, con la capacidad y configuración de burocracias y el perfil de los niños y adolescentes.

Palabras clave: asistencia social, política social, capacidad estatal, eficacia, burocracia

\section{State capacity and effectiveness in the policy of attention to children and adolescents}

The article analyzes the effectiveness of the institutional shelter service for children and adolescents at risk in achieving the goals recommended by ECA: the exceptionality and provisionality of the measure. The argument is that this efficacy is related to the capacity of bureaucracies, derived from their institutional arrangement. The analysis is based on the theoretical discussion of this arrangement, on the mapping of its operational translation and on the evaluation of the service provision configuration. The data that support the analysis are those of the Censo Suas, complemented by information collected in a case study. In a historical perspective, institutional shelter has become a much less recurring measure, but it is still not exceptional, and the provisional nature is related to the nature, location and time of implementation of the units, to the capacity and configuration of the bureaucracies and to the profile of children and adolescents.

Keywords: social welfare, social policy, state capacity, efficiency, bureaucracy 


\section{Introdução}

O intenso esforço de (re)arranjo das políticas sociais brasileiras, ocorrido nas últimas três décadas, tem sido impulsionado por diversos fatores. Entre eles, destacam-se, primeiro, o fortalecimento do sistema de proteção social, evidenciado na ampliação do leque de direitos e no adensamento normativo e organizacional das políticas destinadas à sua garantia; segundo, as severas críticas ao modo de organização e atuação das burocracias públicas, no bojo de uma dinâmica mais geral de redemocratização do Estado; e, por fim, a maturação de um longo aprendizado sobre a natureza e dinâmica de problemas sociais complexos. Combinações diversas entre transversalidade, intersetorialidade, descentralização, incorporação da participação social e formação de redes de gestão têm caracterizado a (re) estruturação organizacional e funcional das estruturas setoriais responsáveis por essas políticas e das relações a serem por elas estabelecidas entre si e com as instâncias de participação social envolvidas na formulação e gestão das ações ${ }^{1}$.

Em termos analíticos, algumas dessas estratégias possuem escopo e objetivos específicos e incidem sobre diferentes etapas do ciclo das políticas, enquanto outras são mais complexas, configurando-se pela combinação de mais de uma dessas estratégias; por exemplo, a gestão em rede, que supõe intersetorialidade, transversalidade, descentralização e incorporação da participação social. No âmbito da gestão, essa superposição se configura como interdependências, supostos que favorecem ou, quando não se verificam, prejudicam a eficácia dessas políticas.

No desenho de políticas específicas, essas estratégias de gestão estruturam o que Gomide e Pires (2014, p. 19-20) denominam "arranjo institucional”, entendido como um "conjunto de regras, mecanismos e processos que definem a forma particular como se coordenam atores e interesses", do qual se deriva a capacidade estatal para a realização dos objetivos por elas preconizados.

A política brasileira de atenção à criança e ao adolescente, especialmente no serviço de acolhimento institucional a crianças e adolescentes em situação de risco, atualmente executado no âmbito do Sistema Único de Assistência Social (Suas), está entre as políticas que apresentam arranjo institucional mais sofisticado, seja pela interdependência das estratégias de gestão que o constituem, seja pela

\footnotetext{
${ }^{1}$ Versões preliminares deste artigo foram apresentadas no I ENEPCP, de 2015, e 39o Encontro da Anpocs, de 2015. Agradecemos a Gilberto Hochman, Renata Bichir e Luiz Mafra as contribuições feitas nessas apresentações; a Jorge Alexandre Neves, o apoio na análise estatística; à equipe do Projeto Rede de Atenção à Criança e ao Adolescente do Município de Belo Horizonte, o empenho no trabalho de campo; à Proex/UFMG, as bolsas de extensão que possibilitaram o desenvolvimento desse projeto; e, por fim, as contribuições dos pareceristas anônimos da Revista do Serviço Público.
} 
diversidade e número dos atores envolvidos e a complexidade dos processos e objetivos preconizados.

Desde sua normatização pelo Código de Menores de 1927, a gestão do que foi denominado "abrigamento de menores" abrangia mais de uma instituição. Com a inflexão estabelecida na trajetória desse serviço pelo Estatuto da Criança e do Adolescente (ECA), em 1990 (Lei no 8.069), no entanto, o número de instituições implicadas em sua gestão ampliou-se significativamente, e as diretrizes para a atuação em rede foram formalizadas. Desde então, a gestão do serviço deve ser desenvolvida de forma intersetorial e transversal, contando com a participação social na formulação, implementação e controle das ações. Entre os objetivos dessa inflexão, está o de colocar fim ao que foi denominado "cultura da institucionalização" (RIZZINI; RIZZINI, 2004), garantindo que a medida protetiva de acolhimento institucional seja aplicada de forma excepcional, isto é, seja a última alternativa de proteção da criança e do adolescente nas situações em que há violação de seus direitos (violência física, violência sexual, por exemplo), e provisória, não devendo ultrapassar o período de dois anos.

O objetivo deste artigo é analisar a eficácia do serviço de acolhimento institucional a crianças e adolescentes em situação de risco na realização desses objetivos ou metas programáticas. Argumenta-se que a complexificação de seu arranjo institucional, em contexto mais geral de adensamento normativo e organizacional do sistema de proteção social, tem criado as condições necessárias a um desempenho bem mais positivo que o verificado nas últimas décadas do século 20. No entanto, ainda há grandes desafios a serem enfrentados, seja no sentido de aprimorar a capacidade das burocracias envolvidas em sua gestão, seja no sentido de tornar sua oferta mais equitativa ao longo do território nacional.

A discussão está organizada em três seções: na primeira, são discutidos os aspectos teóricos das estratégias de gestão e apresentada sua tradução no arranjo institucional do serviço; na segunda, são apresentados os processos, objetos e objetivos em que as diversas burocracias envolvidas estão implicadas e a infraestrutura disponível para a oferta do serviço; por fim, na terceira seção, é analisada a eficácia do serviço na realização das metas de excepcionalidade e provisoriedade da medida acolhimento institucional por meio de análises descritiva e inferencial. As informações que subsidiam essas análises são do Censo Suas², Censo Demográfico e as reunidas no Projeto Rede de Atenção à Criança e ao

\footnotetext{
${ }^{2}$ Realizado pelos órgãos gestores estaduais e municipais do Suas, sob a coordenação do MDSA.
} 
Adolescente do Município de Belo Horizonte ${ }^{3}$. Os dados das duas primeiras fontes (Censo Suas e Censo Demográfico) são utilizados para delinear a configuração do provimento do serviço (número e tipo de unidades e sua distribuição geográfica) e da rede de instituições implicadas em sua implementação, assim como para avaliar sua cobertura e a eficácia na realização da meta de provisoriedade, o que é feito a partir do ajuste e análise de um modelo estatístico de regressão linear. A análise da eficácia na realização da meta de excepcionalidade é feita a partir das informações reunidas no referido projeto, confrontadas com análises constantes em referências bibliográficas e outras publicações na temática, em especial, um relatório da Funabem, de 1984.

\section{Arranjos institucionais das políticas sociais e as inovações do ECA para o acolhimento institucional}

$\mathrm{Na}$ direção do que foi instituído pela Constituição Federal de 1988, o ECA representa importante inflexão no escopo e no arranjo institucional da política de atenção a crianças e adolescentes até então prestada no Brasil.

Arranjo institucional é aqui compreendido como um "conjunto de regras, mecanismos e processos que definem a forma particular como se coordenam atores e interesses" em determinada política pública. Desse arranjo se deriva a capacidade estatal para a realização dos objetivos por ela preconizados (GOMIDE; PIRES, 2014, p. 19-20).

Os autores distinguem dois componentes dessa capacidade do Estado: a habilidade técnico-administrativa e a habilidade política e o fazem com base em aportes teóricos e analíticos do neoinstitucionalismo histórico, em especial o conceito weberiano de burocracia e a centralidade atribuída a esta na (re) construção e implementação das políticas, e atentos ao ambiente institucional estabelecido pela Constituição Federal de 1988, especificamente os "mecanismos para envolvimento dos atores sociais, políticos e econômicos" na formulação e gestão das políticas (GoMIDE; PIRES, 2014, p. 16). A habilidade técnicoadministrativa abrange as "competências dos agentes do Estado para levar a efeito suas políticas, produzindo ações coordenadas e orientadas para a produção de resultados"; a segunda, de natureza política, consiste nas "habilidades da burocracia do Executivo em expandir os canais de interlocução, negociação com

\footnotetext{
${ }^{3}$ A pesquisa empírica foi desenvolvida em 2013, por meio de entrevistas semiestruturadas e questionários fechados para coleta de informações relativas à organização e dinâmica internas das instituições componentes da rede, unidades de acolhimento e suas mantenedoras, trabalhadores das unidades e, com a autorização do Juizado da Infância e da Juventude, crianças e adolescentes.
} 
os diversos atores sociais, processando conflitos e prevenindo a captura por interesses específicos" (GOMIDE; PIRES, 2014, p. 20).

Como antecipado, o estabelecimento de um novo arranjo institucional compõe a inflexão produzida pelo ECA. Essa inflexão é constituída, em primeiro lugar, pelo estabelecimento de uma nova visão da criança e do adolescente: "pessoas em desenvolvimento", "sujeitos de direitos" - e não mais "menores", como denominados nos Códigos de Menores de 1927 (Decreto no 17.943-A) e 1979 (Lei no 6.697), aos quais deve ser garantida proteção integral. Em segundo lugar, o ECA atribui à família, à sociedade e ao Estado o dever de garantir, com absoluta prioridade, às crianças e adolescentes e aos jovens o direito "(...) à vida, à saúde, à alimentação, à educação, ao lazer, à profissionalização, à cultura, à dignidade, ao respeito, à liberdade e à convivência familiar e comunitária" (art. 227). Não é preciso dizer que a tradução dessas ambiciosas diretrizes é um enorme desafio, na medida em que envolve um conjunto relativamente amplo de setores e de instituições e, consequentemente, requer estratégias complexas de gestão, como a transversalidade, intersetorialidade, incorporação da participação social, descentralização e gestão em rede.

A transversalidade, de acordo com Serra (2005), é uma estratégia que busca aumentar a capacidade de atuação das instituições por meio da incorporação de novos "temas, visões, enfoques, públicos, problemas, objetivos etc.". O objetivo é superar os limites a elas colocados por sua especialização funcional e disciplinar, fazendo com que todas "(...) compartilhem sinergicamente a consecução de um objetivo comum que não é específico de nenhuma delas em particular" (SERRA, 2005, p. 4, tradução nossa).

Em termos operacionais, a transversalidade pode ser traduzida de três maneiras: (a) adoção de uma diretriz política mais ampla, um mainstreaming (tema, visão), na oferta dos bens e serviços ofertados tradicionalmente pelas instituições, agregando a eles um "valor novo"; (b) adoção de objetivos comuns (cross-cutting), como qualidade; ou (c) inclusão de mais um público (target-group) no leque dos tradicionalmente atendidos pela instituição.

A primeira e a terceira maneiras de se operacionalizar a transversalidade não são excludentes e, no caso da política de atenção a crianças e adolescentes, devem ser pensadas de forma complementar: a diretriz de absoluta prioridade deve ser traduzida tanto por meio da ampliação da oferta de serviços (por exemplo, educação) e da criação de serviços inexistentes ou residuais (por exemplo, creches) quanto pela ampliação do conhecimento relativo à temática infância e adolescência e pela adoção da visão da criança e do adolescente como "pessoas em desenvolvimento" 
e "sujeitos de direitos", agregando, assim, aos serviços ofertados tradicionalmente um valor novo.

No caso do serviço de acolhimento, a sinergia é esperada na atuação da rede configurada pelo ECA. Com vistas à proteção integral, essa rede abrange: (a) instituições estatais - Juizado da Infância e da Juventude (JIJ), Promotoria de Defesa dos Direitos da Criança e do Adolescente (PJIJ), Defensoria Pública, órgãos gestores da política de assistência social e estruturas setoriais das outras políticas sociais; (b) instituições não estatais, especificamente as instâncias que possibilitam a participação social, seja na prestação do serviço, como as entidades privadas e o Conselho Tutelar (CT), seja em sua formulação e controle, especificamente, os conselhos dos direitos da criança e do adolescente dos níveis municipal, estadual e nacional (CMDCA, CEDCA e Conanda, respectivamente), os conselhos de assistência social também desses três níveis (CMAS, CEAS e CNAS, respectivamente) e, novamente, o CT. Nos termos de Serra (2005), na oferta de seus serviços especializados, essas instituições devem tanto priorizar o atendimento da criança e do adolescente quanto investir na ampliação da oferta e na capacitação das burocracias na temática.

Cabe destacar que a ampliação da oferta de serviços sociais implica também a criação de estruturas organizacionais onde são necessárias. Em um país de grande extensão territorial como o Brasil, esse é um desafio de monta e, no caso da política em foco, adquire proporções ainda maiores, tendo em vista que, entre os direitos de crianças e adolescentes a serem garantidos, está o de convivência familiar e comunitária. Isso exige que o serviço seja prestado na ou próximo à comunidade de origem da criança ou adolescente demandantes, e que as outras instituições que compõem a rede de proteção estejam presentes no município ou na região. Nessa direção, a regulamentação do ECA prevê a presença da PJIJ e do JIJ em todas as comarcas, a do conselho e do órgão gestor da assistência social em todas as unidades federativas e municípios, e, por fim, a do CT e do CMDCA em todos os municípios.

Assim, pode-se dizer que a eficácia da gestão em rede de determinada política social depende de sua efetiva transversalização, o que implica, primeiro, a presença das estruturas previstas nas localidades e regiões em que se fazem necessárias e a ampliação da oferta dos serviços e bens por elas ofertadas, e, segundo, a formação de habilidades burocráticas, de forma que aos bens e serviços setoriais seja acrescido um valor novo.

Em termos conceituais, a rede de gestão é mais bem compreendida a partir do instrumental fornecido pelo modelo de relação do Estado com a sociedade 
denominado "governança pública" (SECCHI, 2009) ou do conceito de "Estado-rede" (CASTELls, 1998). Nessa perspectiva, essa estratégia supõe, para o que interessa aqui, além da própria transversalização, a descentralização de competências na gestão das políticas do nível central para os subnacionais de governo e a participação social em seus processos de definição, implementação e controle (TEIXEIRA, 2002; CASTElls, 1998; SECCHI, 2009).

Em termos normativos, as instituições que constituem determinada rede devem atuar de forma interdependente na realização dos objetivos das políticas. Nessa direção, argumenta-se ainda que, pelo fato de as redes serem policêntricas e os diversos atores que a constituem possuírem recursos e competências diferentes, a dinâmica de sua interação deve ser horizontal, não comportando coordenação centralizada, hierarquia nem controle. A horizontalidade das relações não é ponto de consenso (TEIXEIRA, 2002), especialmente quando a rede abrange instituições não estatais.

Na rede de proteção configurada pelo ECA, combinam-se, no âmbito formal, a horizontalidade nas relações entre instâncias territorial e funcionalmente interdependentes - estruturas do Poder Executivo dos três níveis de governo, JIJ, PJIJ, Defensoria, delegacias e conselhos - com a verticalidade na relação entre órgãos estatais e entidades privadas de assistência social. As estruturas do Executivo são responsáveis pelo financiamento do serviço, como determina a Lei Orgânica da Assistência Social (Loas), enquanto instâncias federais das áreas da assistência social e da criança e do adolescente (Conanda, CNAS e Ministério do Desenvolvimento Social e Agrário - MDSA) são responsáveis pela regulamentação, que pode ser complementada ou adaptada por instâncias subnacionais correlatas. Os governos municipais e estaduais são responsáveis pelo provimento do serviço, sendo que os últimos devem ofertá-lo de forma regionalizada, sempre que a demanda aos municípios não justificar a organização de unidades próprias. Cabe destacar ainda que estados e municípios podem prestar o serviço diretamente ou estabelecer convênios com entidades privadas de assistência social.

Em termos formais, o CT, o conselho de assistência e o de direitos da criança e do adolescente são órgãos funcionalmente autônomos, loci de participação social nos processos de deliberação e controle das ações da área. Os primeiros são constituídos por pessoas eleitas pela comunidade local, e os dois últimos, por representantes governamentais e da sociedade civil. Apesar de a normatização supor a autonomia dessas instâncias, sua vinculação administrativa ao Executivo e, eventualmente, a baixa capacidade técnica e o fraco envolvimento de representantes da sociedade 
civil (SILVA; JACCOUD; BEGHIN, 2009, p. 389) podem torná-las reféns dos interesses do Executivo local e menos capazes de influenciar a formulação das ações ou de exercer seu controle.

Além da transversalidade, a gestão em rede supõe, e sua eficácia depende, da implementação efetiva da intersetorialidade. Cabe lembrar que todas essas estratégias buscam maior sinergia e coordenação entre instituições e estruturas setoriais na solução de problemas complexos, na tentativa de superar os desafios colocados pela especialização funcional e disciplinar. Entre os problemas mais recorrentes, estão a fragmentação, segmentação ou superposição de ações, o desperdício de recursos, as lacunas na prestação de serviços e a competição interinstitucional (MenicCUCI, 2002, JunqueIRA, 2004; SerRA, 2005). Mas há diferenças importantes entre elas. A primeira diz respeito à natureza dos bens e serviços prestados pelas instituições públicas: se por meio da transversalidade, acrescenta-se a eles um valor novo, “(...) sem eliminar nenhuma das dimensões já incorporadas em seu trabalho através da estrutura orgânica básica" (SERRA, 2005, p. 8); na intersetorialidade, supõe-se que os bens e serviços são os tradicionalmente ofertados por "estruturas orgânicas básicas". A segunda diferença entre essas estratégias se refere à responsabilidade por sua implementação.

A responsabilidade pela implementação da transversalidade e da rede se inscrevem prioritamente no âmbito das atribuições dos níveis político e estratégico das instituições; a responsabilidade pela implementação da intersetorialidade, por outro lado, é principalmente das burocracias dos níveis intermediário - que têm a responsabilidade de traduzir decisões em ações (CAVALCANTE; LOTTA, 2015) - e técnico, isto é, as que entregam o serviço à população, no nível da rua (LIPSKY, 1980). Se na transversalidade e na gestão em rede se preconiza que instituições estatais e não estatais atuem de forma concertada na busca de objetivos, temas ou públicos tornados comuns, o que requer atuação privilegiada dos níveis hierárquicos superiores, na intersetorialidade, preconiza-se, por outro lado, uma visão sistêmica de problemas que acometem públicos específicos, salientando-se, especialmente no caso da pobreza ou exclusão, sua origem multicausada e sua natureza multidimensional (BRONZO, 2010; MENICCUCI, 2002; JUNQUEIRA, 2004).

Certamente, o fato de a implementação da transversalidade e da intersetorialidade estar sob a responsabilidade de burocracias diferentes não significa que essa responsabilidade seja exclusiva. Da mesma forma que a transversalidade requer mudanças na forma de atuação dos níveis gerencial e técnico, no sentido de imprimir novos valores aos bens e serviços tradicionalmente ofertados, para que a intersetorialidade se efetive, ela deve ser precedida por comandos formalizados na normatização das políticas, que são possíveis apenas a 
partir de decisões tomadas no nível estratégico das instituições. Mas a indicação de burocracias que devem ter atuação privilegiada em cada estratégia é importante para destacar uma terceira diferença entre elas: o grau de resolutividade. Por estarem referidas aos objetivos institucionais, a eficácia da gestão em rede e da gestão transversal depende da efetividade de comandos hierárquicos e da ressonância que estes encontram nas instituições parceiras no médio ou longo prazo. A eficácia da gestão intersetorial, por outro lado, depende de decisões e ações de médio prazo do nível gerencial e de curtíssimo prazo do burocrata do nível da rua frente a cada situação ou caso atendido.

Assim, a eficácia da gestão em rede no acolhimento institucional de crianças e adolescentes, na realização das metas de excepcionalidade e provisoriedade da medida, enfrenta desafios de monta, entre os quais se destacam os seguintes: primeiro, sua efetiva transversalização, no sentido de priorização desse público por parte de todas as instituições que compõem a rede, traduzida na oferta das estruturas necessárias à formulação e à gestão do serviço nas localidades em que são necessárias; segundo, a capacitação continuada das burocracias envolvidas nos diferentes níveis de gestão do Suas e nas diferentes instituições que compõem a rede, incluindo as que prestam o serviço nas unidades de acolhimento, de forma a imprimir ao serviço um valor novo, qual seja, a visão da criança e do adolescente como pessoas em desenvolvimento, sujeitos de direitos, incluindo o de convivência familiar e comunitária.

No que se refere à capacitação dos profissionais envolvidos no gerenciamento e prestação desse serviço, é importante destacar a inexistência de iniciativas nacionais continuadas ${ }^{4}$. Nos governos subnacionais, a formação desses profissionais tem ocorrido de forma fragmentada, configurando um quadro bastante heterogêneo, conforme chama a atenção Bichir (2015), que é o mesmo encontrado no âmbito do Judiciário e do Ministério Público, conforme informações coletadas na rede de proteção do município de Belo Horizonte.

No que se refere à disponibilização de estruturas necessárias à composição da rede em cada região ou município, também se verifica um longo caminho a ser trilhado. Apesar dos avanços, em muitos municípios e regiões, a rede ainda é incompleta e a estrutura de provimento insuficiente, indicando falhas na tranversalização da política, como será visto na próxima seção.

\footnotetext{
${ }^{4}$ A iniciativa nacional pioneira de capacitação - o Programa Nacional de Capacitação dos Trabalhadores do Suas (Capacita Suas) - começou a ser implementada em 2013, mas ainda se restringe aos trabalhadores da estrutura direta dos governos municipais e estaduais, excluindo-se, assim, os que se vinculam às entidades privadas prestadoras do serviço de acolhimento e os conselheiros (de assistência social, de direitos e tutelares).
} 


\section{Arranjo institucional e configuração da rede de gestão do serviço de acolhimento institucional a crianças e adolescentes}

Nos termos das normativas que regulamentam o ECA, as habilidades técnicoadministrativa e política das burocracias envolvidas na gestão do serviço de acolhimento institucional traduzem-se basicamente em atividades de interlocução interinstitucional e intersetorial. Essas atividades antecedem a própria aplicação de medidas específicas de acolhimento institucional e se estendem por toda a sua vigência, isto é, no atendimento da criança e adolescente e de sua família.

Antes da aplicação da medida de acolhimento, essa interlocução tem como foco, no âmbito estratégico, a própria construção da rede de proteção, incluindo a de provimento do serviço no nível local (ou regional), e, no âmbito operacional, a análise da adequação da medida a casos específicos.

Na configuração do provimento, JIJ, PJIJ, CT e órgão gestor da assistência social compartilham a responsabilidade de controlar tanto a compatibilidade entre demanda e oferta de vagas quanto a qualidade do serviço prestado. Para tanto, os três primeiros devem fiscalizar as unidades de acolhimento, emitindo (ou não) atestados de qualidade e eficiência do serviço, os quais subsidiam a renovação de seu registro no CMDCA, ou a aprovação, também por esse conselho, dos programas de atendimento desenvolvidos por entidades privadas e governos. No caso de haver oferta insuficiente de vagas, inadequação de infraestrutura ou das equipes técnicas, o Executivo municipal pode ser intimado pela PJIJ ou JIJ a fazer as adequações necessárias. Se for necessária a criação de unidades novas, o CMDCA deve fazer o credenciamento dos pleiteantes. No caso de entidades privadas, esse credenciamento é exigido também para o estabelecimento de convênios com o poder público, o que Ihes possibilitará receber pagamento mensal por pessoa acolhida ou vaga contratada.

A interlocução interinstitucional de natureza operacional inicia-se com a aplicação da medida de acolhimento, prevista no art. 101 do ECA. As situações que a justificam são o abandono, derivado de orfandade ou não, e a violação de direitos (violência física, psicológica e sexual ou negligência, exploração sexual e trajetória de vida nas ruas, acompanhada ou não de mendicância ou trabalho infantil). Por eventualmente implicar suspensão ou destituição do poder familiar, o abrigamento só pode ser feito mediante a emissão de Guia de Acolhimento pelo JIJ. Em casos emergenciais, o CT pode emitir uma requisição, garantindo, assim, a proteção imediata da criança ou adolescente. A decisão pelo abrigamento deve estar sempre subsidiada por um estudo diagnóstico.

Esse estudo é a primeira das seis orientações que compõem as Orientações Técnicas: Serviços de Acolhimento para Crianças e Adolescentes, de 2009, que 
prescrevem procedimentos a serem desenvolvidos pelas instituições que integram a rede, na tentativa de garantir a excepcionalidade e provisoriedade da medida de acolhimento.

O estudo diagnóstico deverá ser complementado pela equipe das unidades de acolhimento na elaboração do plano individual de atendimento (PIA), que é a segunda orientação. Neste, devem ser definidas todas as atividades a serem realizadas com a criança ou adolescente, com vistas à sua reintegração na família de origem ou substituta. Obviamente, para isso é necessário o atendimento da família, que é a terceira orientação técnica. A articulação intersetorial e interinstitucional é a quarta orientação, que estabelece que a burocracia faça interlocução estreita com os programas e serviços sociais da rede local ou regional, em especial os de saúde, educação e assistência social. Por fim, as quinta e sexta orientações técnicas estabelecem os parâmetros de organização e funcionamento das unidades de acolhimento, a serem formalizados em um projeto político-pedagógico (PPP) que deve ser aprovado pelo órgão gestor.

Esta é, pois, a tradução das estratégias de gestão no arranjo do serviço de acolhimento a crianças e adolescentes em situação de risco, do qual se supõe derivar a capacidade estatal necessária à realização de seus objetivos. Embora esse nexo causal seja plausível, cabe destacar que o argumento supõe, no caso em tela, a efetiva transversalização da atenção à criança e ao adolescente, no sentido de disponibilização, por parte de todas as instituições que compõem a rede, das estruturas e burocracias necessárias à sua implementação ao longo do território nacional. Logicamente, pouco (ou nada) adianta construir arranjos institucionais conducentes à eficácia na realização de metas, se não se disponibilizam os recursos, competências e habilidades necessários à sua implementação.

Certamente, não se espera que haja órgãos do Judiciário e Ministério Público destinados à infância e à juventude, especificamente juízos e promotorias de justiça, em todos os municípios, dado que a referência de localização dessas instituições é a comarca ${ }^{5}$, assim como não se prevê a existência de Centro de Referência Especializado de Assistência Social (Creas). Como os serviços especializados de saúde, esses centros podem ser ofertados regionalmente, cobrindo grupos de municípios de pequeno porte, sob a coordenação ou não dos governos estaduais, conforme previsto na NOBSuas, de 2012. As unidades de acolhimento, no entanto, devem estar, de acordo com regulamentação ${ }^{6}$, situadas na ou próximas à comunidade de origem das crianças

\footnotetext{
${ }^{5}$ Conforme a Lei Orgância Nacional do Ministério Público (Lei no 8.625, de 1993), a distribuição das promotorias segue a das comarcas do Judiciário.

${ }^{6}$ Orientações Técnicas: Serviços de Acolhimento para Crianças e Adolescentes; Norma Operacional Básica do Sistema Único de Assistência Social; Tipificação Nacional de Serviços Socioassistenciais.
} 
e adolescentes, de forma a se preservar seu direito à convivência comunitária e a facilitar o atendimento da família, e a uma distância razoável da sede das comarcas e dos serviços sociais regionalizados, se for o caso, de forma a possibilitar a supervisão do serviço e a interlocução durante sua prestação.

A essas exigências de configuração da rede se somam aquelas referidas à estrutura de provimento do serviço. Colocando fim às grandes instituições (orfanatos, internatos), o ECA estabelece que o atendimento em abrigos deve ser personalizado e em pequenos grupos. Na regulamentação dessa determinação, as Orientações Técnicas estabelecem que o acolhimento deve ser feito em unidades que abriguem, no máximo, 20 e 10 crianças e adolescentes, nas modalidades abrigo institucional e casa-lar, respectivamente. Atualmente, esse provimento é constituído por unidades governamentais municipais e estaduais e não governamentais (entidades privadas), que podem ser ou não conveniadas com o poder público.

Cabe lembrar que essa configuração híbrida (pública e privada) tem origem no Código de Menores de 1927, que determinou a criação de estruturas federais, mas abriu a possibilidade de oferta do serviço em instituições privadas. Respondendo a essa normatização, o Governo Vargas investiu na construção de estruturas públicas (o Serviço de Assistência ao Menor - SAM) e forneceu incentivos financeiros e fiscais às entidades privadas, possibilitando a elas protagonizarem, sob a liderança da Legião Brasileira de Assistência Social (LBA), a prestação deste e outros serviços socioassistenciais. Essa configuração permaneceu até o início da década de 1960, quando o Regime Militar, no processo mais geral de reestruturação do sistema de proteção social, transformou a LBA em fundação pública, retirando dela praticamente todos os recursos financeiros anteriormente designados. Apesar disso, as entidades privadas continuaram a protagonizar a prestação do serviço de abrigamento, a partir de então, sob o comando da Fundação Nacional do Bem-Estado do Menor (Funabem) e Fundações Estaduais de Bem-Estar do Menor (Febem).

É sobre o legado deixado por essa trajetória que tem sido construído o provimento do atual serviço de acolhimento institucional para crianças e adolescentes no Suas. Mas, apesar dos esforços que têm sido empreendidos no âmbito desse sistema, a oferta ainda é insuficiente, desigualmente distribuída no território nacional e concentrada nas grandes cidades. Os dados da Tabela 1 permitem a avaliação do quadro.

Como pode ser observado, em 2013, havia 2.464 unidades de acolhimento institucional com registro no Censo Suas, sendo $98,5 \%$ delas destinadas a crianças e adolescentes, e o restante, a crianças e adolescentes com deficiência ${ }^{7}$. Desse total, a maioria é de natureza não governamental, e o restante está sob a responsabilidade

\footnotetext{
${ }^{7}$ Essas unidades estão em franco processo de desaparecimento por contrariarem a diretriz transversal de não segregação das pessoas com deficiência, estabelecida pela Lei no 7.853, de 1989.
} 
direta dos governos municipais e estaduais. Das unidades não governamentais, quase todas $(89,2 \%)$ mantêm convênio com governos municipais.

Tabela 1 - Unidades de acolhimento a crianças e adolescentes, população menor de 18 anos, pessoas acolhidas e estimativa de cobertura do serviço, por região (\%)

\begin{tabular}{|c|c|c|c|c|c|c|}
\hline \multirow[b]{2}{*}{ Região } & \multicolumn{3}{|c|}{ Unidades (2013) } & \multirow{2}{*}{$\begin{array}{c}\text { População } \\
\text { menor } 18 \\
\text { anos (2010) }\end{array}$} & \multirow{2}{*}{$\begin{array}{c}\text { Pessoas } \\
\text { acolhidas } \\
\text { (vagas) (2013) }\end{array}$} & \multirow{2}{*}{$\begin{array}{l}\text { Cobertura } \\
\text { estimada* }\end{array}$} \\
\hline & $\begin{array}{c}\text { Não } \\
\text { governamental }\end{array}$ & $\begin{array}{c}\text { Governa- } \\
\text { mental. }\end{array}$ & Total & & & \\
\hline Nordeste & 4,8 & 6,2 & 11,0 & 30,7 & 13,4 & 26,4 \\
\hline Sudeste & 31,5 & 18,0 & 49,5 & 38,1 & 52,4 & 83,2 \\
\hline Norte & 0,7 & 3,5 & 4,2 & 10,6 & 3,7 & 21,3 \\
\hline C-Oeste & 3,2 & 5,0 & 8,2 & 7,5 & 7 & 56,6 \\
\hline Sul & 12,4 & 15,2 & 27,6 & 13,2 & 23,4 & 107,5 \\
\hline Brasil (N) & 1.288 & 1.176 & 2.464 & 56.290 .168 & 34.014 & - \\
\hline Brasil (\%) & 52,3 & 47,7 & 100,0 & 100,0 & 100,0 & 60,4 \\
\hline
\end{tabular}

Fontes: MDSA. Censo Suas 2013; IBGE. Censo Demográfico 2010. Elaboração própria.

* Estimativa feita a partir da subtração do número de pessoas acolhidas (vagas), indicado no Censo Suas, do número de habitantes com menos de 18 anos de cada região, indicado no Censo Demográfico.

A distribuição das unidades nas cinco regiões do país, e a relação entre essa distribuição e a de pessoas com menos de 18 anos, que constituem o público potencial do serviço ${ }^{8}$, e a de pessoas acolhidas (tomada aqui como equivalente ao número de vagas) indicam forte desequilíbrio: a Região Nordeste, por exemplo, concentra $11 \%$ das unidades de acolhimento, 13,4\% das pessoas acolhidas (portanto, das vagas) e 30,7\% das pessoas com menos de 18 anos, pouco menos que a Sudeste, que possui $38,1 \%$ dos habitantes nessa faixa etária, mas concentra $49,5 \%$ das unidades e $52,4 \%$ das vagas.

Certamente, essa análise não permite inferir escassez e má-distribuição na oferta, pois está ancorada apenas na indicação do público potencial (população menor de 18 anos) e não em um diagnóstico rigoroso da demanda pelo serviço. A mensuração dessa demanda exigiria dados relativos à incidência territorial das diferentes violações de direitos das crianças e adolescentes e à configuração e dinâmica da rede de proteção local. Isso porque esses fatores (configuração e dinâmica da rede) podem não apenas contra-arrestar e prevenir a incidência ou

\footnotetext{
${ }^{8}$ Cabe ressaltar que o público potencial do serviço de acolhimento é toda a população menor de 18 anos. Como ocorre nos outros serviços especializados do Suas (média e alta complexidades), o critério de acesso é a ameaça ou violação de direitos, que podem ocorrer, e efetivamente ocorrem, em todas as classes sociais. Os testes de meios, para verificar a situação de pobreza ou indigência, são exigidos apenas para o acesso a benefícios continuados ou eventuais de transferência de renda.
} 
agravamento das situações de violação de direitos, mas também apoiar as famílias que nelas incorrem, evitando-se, assim, a aplicação da medida de acolhimento.

Por isso, uma alternativa para avaliar a demanda (e, assim, se há escassez) é tomar definições operacionais para mensurá-la, como as que foram pactuadas no âmbito da Comissão Intergestores Tripartite (CIT) para ampliar a oferta de vagas (com cofinanciamento federal): mínimo de 0,5 e máximo de uma vaga para cada mil crianças e adolescentes residentes na localidade ${ }^{9}$. Considerando a razão de uma vaga por mil habitantes como uma estimativa de demanda mais realista, pois alguns estados já a superam, e ainda tomando o número' total de acolhidos nas 2.464 unidades (total de 34.014$)^{10}$ como equivalente ao número de vagas existentes, verifica-se grande variação nos níveis de cobertura entre as regiões (conforme a última coluna da Tabela 1, de 21,3\%, na Norte, a 107,5\%, na Sul).

Se essa análise permite concluir pela distribuição desigual do serviço no território nacional, os dados mostram também sua concentração nos municípios maiores: as 2.464 unidades estão localizadas em apenas 1.296 municípios (23,3\%), a maioria de grande porte ou metrópole, o que contraria a diretriz de que o serviço deve ser prestado na ou próximo à comunidade de origem do acolhido. As regiões com menor número de municípios que contavam com o serviço de acolhimento eram a Nordeste ( $8 \%$ dos municípios) e a Norte $(16,9 \%)$; nas regiões Sudeste, Sul e Centro-Oeste, o serviço era ofertado em $34,2 \%, 31,1 \%$ e $29,2 \%$ dos municípios, respectivamente.

Os dados do Censo Suas mostram também que parte pequena dessa estrutura de provimento foi construída antes do surgimento do ECA $(1,4 \%$ de unidades governamentais e $12,3 \%$ de unidades não governamentais) e que houve intenso esforço governamental, especialmente municipal, na criação de novas unidades, após o surgimento do Suas, em 2005. Do ECA ao surgimento do Suas, o percentual de unidades governamentais e não governamentais criadas é praticamente equivalente (18,8\% e $18,5 \%$, respectivamente) mas, após o surgimento do Suas, o número de unidades governamentais criadas foi maior que o de não governamentais ( $27,5 \%$ e $21,4 \%$, respectivamente), sendo esta a tendência em todas as regiões do país, exceto na Sudeste ${ }^{11}$. Por fim, cabe destacar que o percentual de unidades governamentais e não governamentais criadas a partir de 2009 foi $15,7 \%$ e $14,5 \%$, respectivamente.

\footnotetext{
${ }^{9}$ Resolução CIT no 15, de 5 de setembro de 2013.

${ }^{10}$ MDSA. Censo Suas de 2013 (questões q12a_1 a q12b_10 e q12_SI).

${ }^{11} \mathrm{~A}$ prevalência das governamentais corresponde a 2,8\%, 2,8\%, 1,8\% e 1,4\% nas regiões Sul, Norte, Centro-Oeste e Nordeste, respectivamente. Na Sudeste, havia 13,2\% unidades não governamentais a mais que governamentais.
} 
Desse desenvolvimento, merecem destaque dois aspectos: primeiro, a tendência de maior proatividade estatal no provimento do serviço, especialmente em regiões ou municípios em que a presença de entidades privadas é mais rarefeita, revertendo assim a tendência histórica de sua concentração nas regiões Sudeste e Sul; segundo, o fato de que grande parte do provimento $(69,8 \%)$ é constituída por unidades criadas antes da regulamentação do acolhimento institucional estabelecido pelo ECA, em 2009, o que indica a necessidade de um esforço nacionalmente coordenado de capacitação das burocracias dos níveis gerencial e técnico.

Ainda por referência à configuração do provimento do serviço, é preciso salientar, tendo em vista os objetivos da análise aqui desenvolvida, duas dimensões de sua estruturação: as modalidades de acolhimento institucional e as burocracias que prestam o atendimento nas unidades. No que se refere às primeiras, a previsão da normatização, como antecipado, é que o acolhimento de crianças e adolescentes seja feito nas modalidades abrigo institucional e casalar. No entanto, o Censo Suas indica que o acolhimento também tem sido feito em casas de passagem (que representam 6,6\% das 2.464 unidades), as quais, de acordo com a Tipificação Nacional, destinam-se a abrigamento provisório de diferentes segmentos; em residências inclusivas $(0,4 \%)$, destinadas a adultos e idosos com deficiência; e em unidades que ainda não se adequaram à Tipificação Nacional (1,6\%).

A importância da obediência às exigências quanto às modalidades de acolhimento deriva, entre outras coisas, do fato de que elas vêm acompanhadas de orientações específicas para a formação das equipes de trabalho. De acordo com as Orientações Técnicas, as equipes que prestam o serviço em unidades da modalidade abrigo institucional e casa-lar devem contar com pelo menos um coordenador e dois profissionais com nível superior (psicólogo e assistente social), para cada grupo de 20 acolhidos, e um cuidador e um auxiliar para cada grupo de dez, diminuindose essa proporção quando houver criança ou adolescente que demande cuidados especiais (deficiência ou idade inferior a um ano).

Estes são, pois, os parâmetros e os limites do provimento do serviço, entre os quais se destacam a distribuição desigual da oferta entre as regiões e concentrada nas cidades maiores e o predomínio de unidades criadas antes da vigência da normatização atual.

No que se refere à rede de proteção, resta avaliar a disponibilização das estruturas das outras instituições no município ou região em que se localiza a unidade de acolhimento. Na Tabela 2, apresentam-se dados relativos à existência, no município da unidade de acolhimento, de instâncias de supervisão/fiscalização e de serviços sociais com os quais elas devem manter interlocução. 
Tabela 2 - Unidades de acolhimento em municípios que não possuem instâncias de controle e estruturas de serviços sociais, por região e natureza - Brasil (2013) $(\mathrm{N}=\mathbf{2 . 4 6 4})(\%)^{(1)}$

\begin{tabular}{c|c|c|c|c|c|c|c|c}
\hline \multirow{2}{*}{$\begin{array}{c}\text { Região } \\
\text { Natureza }\end{array}$} & \multicolumn{4}{|c|}{ Controle $^{(2)}$} & \multicolumn{4}{c}{ Serviços sociais } \\
\cline { 2 - 9 } & CT & SMAS & Judiciário & $\begin{array}{c}\text { Minist. } \\
\text { Público }\end{array}$ & Cras & Creas & Saúde & Educação \\
\hline Sudeste & 0,1 & 0,1 & 0,5 & 0,8 & 0,6 & 15,9 & 0,2 & 1 \\
Sul & 0,0 & 0,6 & 0,4 & 0,1 & 0,4 & 20,3 & 0,4 & 0,1 \\
C-Oeste & 0,0 & 2,0 & 0 & 0,5 & 0,5 & 12,4 & 0 & 1,5 \\
Nordeste & 0,0 & 0,4 & 0,4 & 0,4 & 0 & 2,6 & 0,4 & 0 \\
Norte & 0,0 & 0,0 & 0,9 & 0,9 & 0 & 12 & 0 & 0 \\
\hline Não Gov. & 0,1 & 0,3 & 0,3 & 0,3 & 0,5 & 9,4 & 0,2 & 0,7 \\
Gov.Mun. & 0,0 & 0,5 & 0,6 & 0,9 & 0,3 & 21,7 & 0,3 & 0,6 \\
Gov.Est. & 0,0 & 0,0 & 0,0 & 0,0 & 0,0 & 14,3 & 0,0 & 0,0 \\
\hline Brasil(N) & 1 & 10 & 10 & 32 & 11 & 374 & 6 & 16 \\
Brasil(\%) & 0,04 & 0,41 & 0,41 & 0,53 & 0,41 & 15,02 & 0,24 & 0,61 \\
\hline
\end{tabular}

Fontes: MDSA. Censo Suas 2013; IBGE. Elaboração própria.

(1) Percentuais calculados por referência aos totais de unidades de cada região e de cada natureza.

(2) Não há informação no Censo Suas sobre existência do CMDCA no município da unidade.

Em nível nacional, os serviços de interlocução obrigatória menos presentes nos municípios em que se situam as unidades são os dos Creas: 15,02\% das unidades não contam com os serviços desse equipamento. Por outro lado, a ausência de serviços de educação, saúde e de proteção básica do Suas ocorre nos municípios de menos de $1 \%$ das unidades. Quanto às instituições de controle, a que está menos presente é o Ministério Público. A inexistência do CT ocorre no município de apenas uma unidade, e a do órgão gestor da assistência social (secretaria municipal) e do Poder Judiciário, nos municípios de dez unidades. Observa-se, ainda, que as unidades governamentais, assim como as das regiões Sudeste e Sul, são as que menos contam com a presença de instâncias de controle e estruturas de serviços sociais nos municípios em que se localizam. Considerando que essas instituições e estruturas estão mais difundidas nos municípios grandes, esse achado indica que as unidades governamentais de acolhimento são relativamente mais recorrentes, nessas duas regiões, nos municípios de porte menor.

Assim, em nível nacional, verifica-se desempenho relativamente bom das instituições que compõem a rede de proteção à criança e ao adolescente na estratégia de transversalização, pelo menos no sentido de disponibilização das estruturas necessárias à gestão do serviço nas localidades em que o serviço está sendo ofertado. O maior problema surge nesse último aspecto: a oferta do serviço está desigualmente distribuída no território nacional, concentrada nas cidades maiores e constituída por um grande número de unidades criadas antes da regulamentação do arranjo institucional estabelecido pelo ECA. 
Delineados o arranjo institucional do serviço, a configuração da rede de proteção e o seu provimento, cabe avaliar a eficácia de sua gestão na realização das metas programáticas de excepcionalidade e provisoriedade.

\section{Excepcionalidade e provisoriedade do acolhimento institucional}

A denominada "cultura de institucionalização" é vista por Rizzini e Rizzini (2004) como fator explicativo do modelo de atenção a "menores abandonados e deliquentes" configurado pelo Código de Menores de 1927 e mantido mesmo após o Código de 1979 ter preconizado o direito à convivência familiar e comunitária. No entendimento das autoras, a principal evidência seria a adoção do abrigamento como a primeira (senão única) alternativa de proteção (incluindo educação) de crianças e adolescentes pobres.

Embora não haja registros consistentes do número de crianças e adolescentes em situação de abrigamento ao longo do século 20, e dos motivos que o ensejaram, as evidências indicam diminuição dessa prática e, portanto, eficácia, em relação ao período anterior ao ECA, na realização da meta de excepcionalidade da medida de acolhimento institucional. Entre os registros mencionados por Rizzini e Rizzini (2004, p. 39), talvez mereça algum crédito o Relatório Anual de 1984, da Funabem, informando que, dos 504.379 atendimentos daquele ano, apenas $8 \%$ foram feitos sob regime de internação, o que corresponde a 40.350 crianças e adolescentes. Esse número é maior que o constatado no Levantamento Nacional das Crianças e Adolescentes em Serviços de Acolhimento, de 2009 (ASSIS; FARIAS, 2013), que é de 36.929, e que o registrado no Censo Suas de 2013, que é de $31.787^{12}$ crianças e adolescentes. Cabe destacar que essa diminuição no número de abrigamentos adquire relevo ainda maior se considerarmos o crescimento da população nesses últimos 30 anos.

Essa diminuição do número de abrigamentos, nos últimos 30 anos, certamente indica o aumento de alternativas de cuidado. Como argumentado, esse quadro resulta de um processo mais geral de fortalecimento do sistema de proteção social, resultante da ampliação do leque de direitos sociais e do correspondente adensamento normativo e organizacional das políticas destinadas à sua garantia.

Apesar desse avanço e de seu inegável impacto no número de crianças e adolescentes abrigados, os dados do levantamento e do survey realizado em Belo Horizonte mostram que o acolhimento ainda não adquiriu o caráter excepcional preconizado pelo ECA. No levantamento, verificou-se que os três principais motivos que ensejam o acolhimento são a negligência (33,2\% das crianças e adolescentes), o

${ }^{12}$ Dos 34.014 acolhidos, 93,5\% têm até 17 anos; 4,8\%, 18 ou mais; para 1,7\%, não há informações. 
abandono (18,5\%) e a toxicomania dos pais $(17,7 \%)$. Considerando que o abrigamento deve ser motivado por violação de direitos, há problemas especialmente com a categoria "negligência", pois sua interpretação, como destacado por Assis e Farias (2013, p. 177), “(...) é marcada por forte carga subjetiva do profissional”, que, muitas vezes, a confunde com pobreza.

No survey, a esses motivos se somam outros que também não justificam o acolhimento institucional, como mostrado no Gráfico 1.

\section{Gráfico 1 - Crianças e adolescentes em unidades de acolhimento por faixa etária e motivo de acolhimento - BH (2013) ( $N=462)(\%)$}

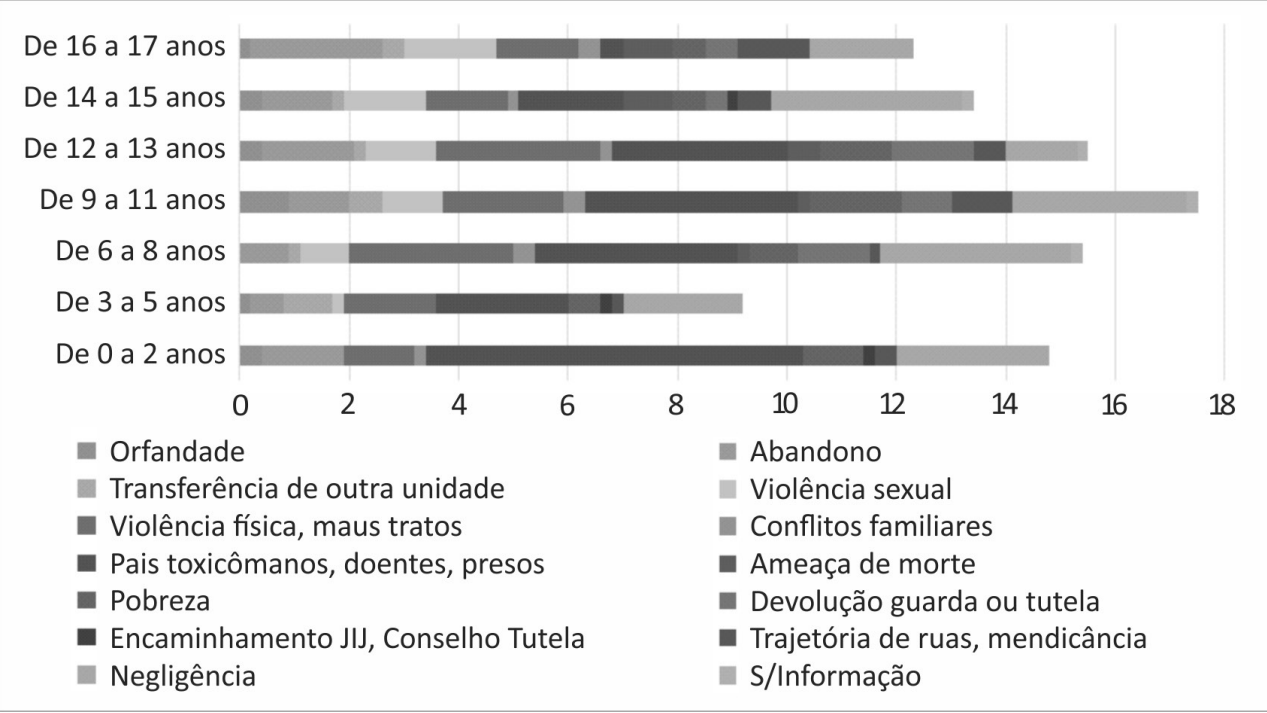

Fonte: Projeto Rede de Atenção à Criança e Adolescente. Elaboração própria.

Entre os principais motivos do acolhimento ${ }^{13}$, estão a toximania ou doença dos pais ( $22,7 \%$ do total), incidindo principalmente na faixa etária de 0 a 2 anos; a negligência (18,6\%), que se distribui por todas as faixas; a violência física $(14,5 \%)$, mais recorrente a partir dos 6 anos; o abandono (9,5\%), mais recorrente na faixa de 0 e 2 anos e a partir dos 12 anos; e a pobreza (6,9\%), presente em todas as faixas etárias. Foram verificados outros motivos que também não deveriam existir, como a devolução de guarda ou tutela, que indica inserção familiar apressada, e o de conflitos familiares, que, como a pobreza e a negligência, pode indicar escassez de serviços sociais locais.

\footnotetext{
${ }^{13} \mathrm{Em}$ resposta a essa pergunta, os técnicos tiveram liberdade para registrar diversos motivos, sendo a negligência recorrentemente mencionada isoladamente ou junto com outros motivos. No tratamento dos dados, ela foi tomada como motivo principal apenas quando indicada isoladamente.
} 
Gráfico 2 - Crianças e adolescentes por motivo de acolhimento e sexo - BH (2013) $(\mathrm{N}=462)(\%)$

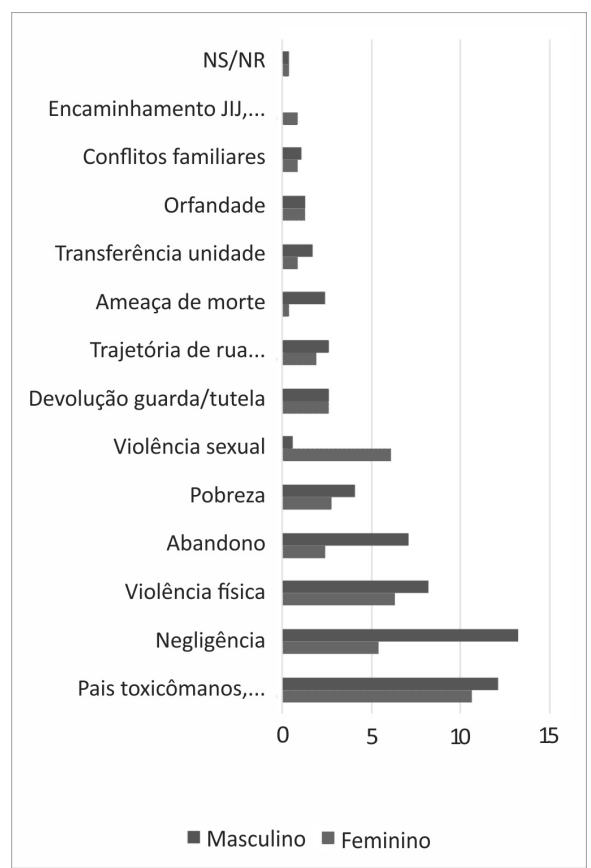

Fonte: Projeto Rede de Atenção à Criança e Adolescente. Elaboração própria.

Gráfico 3 - Crianças e adolescentes por existência ou não de condição que exige cuidados especiais e tipo de condição e motivo de acolhimento - BH (2013) (N = 462) (\%)

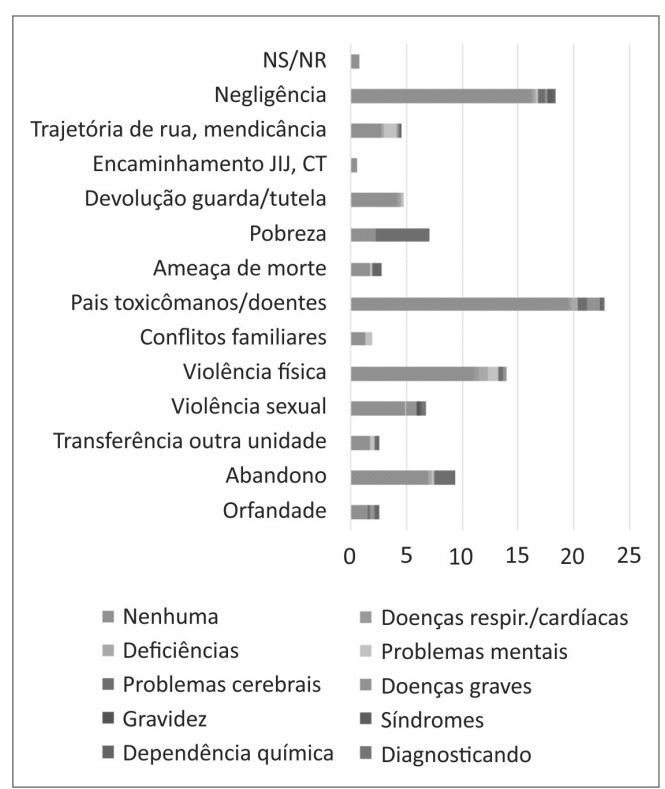

Fonte: Projeto Rede de Atenção à Criança e Adolescente. Elaboração própria. 
Gráfico 4 - Crianças e adolescentes por existência ou não de condição que exige cuidados especiais e tipo de condição e tempo de acolhimento - BH (2013) (N = 462) (\%)

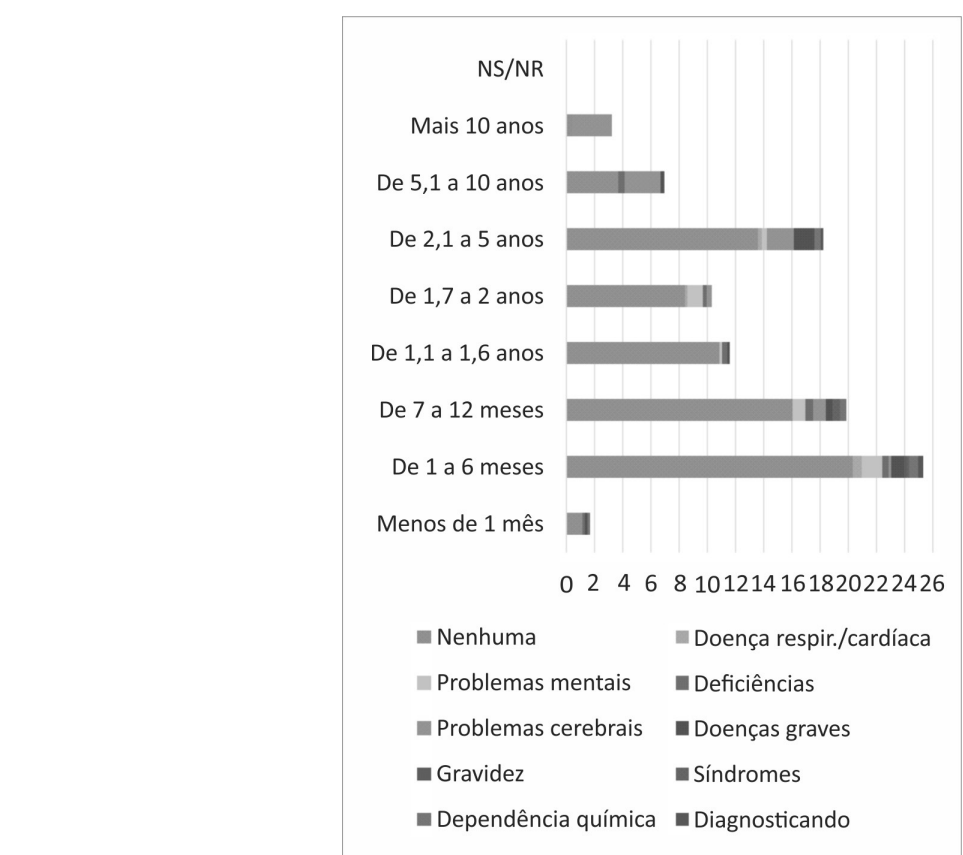

Fonte: Projeto Rede de Atenção à Criança e Adolescente. Elaboração própria.

Sendo a maioria dos acolhidos do sexo masculino, a grande maioria das violações, como mostra o Gráfico 2, incide mais sobre eles, exceto a violência sexual, que atinge principalmente as meninas, e a orfandade, que ocorre nos dois sexos. Cabe destacar que, como mostrado no Gráfico 3, das 462 crianças e adolescentes investigados, 24,9\% apresentam alguma condição que exige cuidados especiais, principalmente problemas cerebrais (paralisia etc.) e mentais (esquizofrenia etc.) e as doenças graves (sífilis, HIV etc.).

A natureza das violações e a condição física dos acolhidos também impactam negativamente a meta de provisoriedade. No Gráfico 4, verificam-se algumas relações entre o tempo de acolhimento e a condição física, sendo duas as principais: entre os que possuem entre dois e cinco anos de acolhimento, os problemas cerebrais e mentais são mais frequentes; entre os acolhidos entre cinco e dez anos e há mais de dez, os que possuem problemas cerebrais são quase a metade e quase a totalidade, respectivamente.

Para a análise da eficácia da gestão na realização da meta de provisoriedade da medida de acolhimento de crianças e adolescentes em nível nacional, utiliza-se aqui a regressão linear pelo método dos mínimos quadrados ordinários, tendo-se como 
variável dependente o quadrado do percentual de pessoas acolhidas na unidade por, no máximo, dois anos.

O universo dessa análise são as 2.464 unidades destinadas a crianças e adolescentes com e sem deficiência registradas no Censo Suas 2013. A análise fazse a partir de três modelos, correspondentes a três blocos de variáveis indicadoras, cuja fonte é também o Censo Suas. O primeiro modelo é constituído por variáveis relativas ao contexto e à estrutura do provimento do serviço; o segundo, pelas variáveis do primeiro modelo acrescidas de variáveis indicadoras da capacidade burocrática, em sua dimensão técnico-administrativa e política; por fim, o terceiro modelo é constituído pelas variáveis do segundo, acrescidas de variáveis indicadoras da equipe de trabalho da unidade e do perfil das pessoas nela acolhidas ${ }^{14}$.

O primeiro modelo é constituído por cinco dimensões (a região do país e o porte do município em que se localiza a unidade, a natureza desta, a modalidade do acolhimento por ela ofertado e o tempo decorrido desde sua implantação). As quatro primeiras se desdobram em variáveis indicadoras binárias, e a última é representada por uma variável númerica: (1) regiões Nordeste, Norte, Sul e CentroOeste, por referência à Sudeste; (2) municípios de porte pequeno (até 50.000 habitantes) e médio (de 50.001 até 100.000 habitantes) por referência a municípios de porte grande (mais de 100.000 habitantes) ${ }^{15}$; (3) modalidade de acolhimento casa de passagem e residência inclusiva/outra, por referência às modalidades abrigo e casa-lar; (4) unidades de natureza não governamental com convênio, não governamental sem convênio e governamental estadual, por referência às de natureza governamental municipal; (5) número de meses de implantação da unidade ${ }^{16}$.

As hipóteses de análise desse primeiro modelo são as seguintes: apresentam maior eficácia na realização da meta de provisoriedade do acolhimento as unidades (a) localizadas em regiões e municípios que possuem redes de serviços mais densas (Sudeste e Sul e municípios de grande porte), em virtude da facilidade de se implementar a intersetorialidade; (b) governamentais, em virtude da vinculação mais próxima com os órgãos gestores da assistência social, quando comparadas às não governamentais, especialmente as que não possuem convênio com o poder público municipal; (c) mais novas, em especial as criadas após a implantação do Suas e a aprovação da regulamentação do arranjo instituído pelo ECA; (d) configuradas

\footnotetext{
${ }^{14} \mathrm{O}$ Quadro 1, no apêndice, apresenta descrição detalhada das variáveis resposta e explicativas do modelo de regressão linear

${ }^{15}$ Categorização feita a partir dos dados do Censo Demográfico de 2010 (IBGE).

${ }^{16}$ Calculado por referência à data de 31/07/2013. As unidades implantadas após essa data receberam o valor ' 0 ' como tempo de implantação.
} 
como casas de passagem, dado que o acolhimento nelas ocorre apenas enquanto não se disponibiliza vaga em abrigo institucional e casa-lar, seguidas pelas unidades configuradas como abrigo e casa-lar, dado que são as instituições específicas para crianças e adolescentes, e pelas residências inclusivas, que não se destinam mais, conforme a normatização atual, a crianças e adolescentes.

No segundo modelo, são acrescentadas quatro variáveis indicadoras da capacidade burocrática. As três primeiras são binárias: unidades que contam com (1) fiscalização da SMAS; (2) fiscalização do CT/CMDCA e (3) fiscalização do JIJ/ PJIJ, por referência às que não contam, e a última é contínua: (4) índice que mede a articulação/ interlocução entre a unidade acolhimento e o JIJ, estruturas de assistência social (SMAS, Cras e Creas), de educação e de saúde ${ }^{17}$. As hipóteses são as de que apresentam maior eficácia na realização da meta de provisoriedade as unidades (a) mais fiscalizadas por essas instâncias de controle e as que (b) mantêm maior interlocução intersetorial e interinstitucional, ou seja, as unidades que se inserem em redes interinstitucionais e intersetoriais que contam com burocracias mais habilitadas.

Às variáveis que compõem o segundo modelo acrescentam-se, no terceiro, mais cinco, que informam sobre o perfil dos acolhidos e da equipe técnica. O objetivo é avaliar o impacto do tamanho dessas equipes, por referência ao número e o perfil dos acolhidos, e das exigências normativas para sua configuração, no que se refere à formação dos profissionais, sobre a meta de provisoriedade da medida de acolhimento. São elas: (5) percentual de acolhidos com deficiência, por referência ao total de acolhidos da unidade, e as quatro últimas, binárias: unidades que possuem percentual de crianças em idade de 0 a 5 anos (6) entre $1 \%$ e 24\%; (7) entre 25 e $49 \%$; (8) entre $50 \%$ e $74 \%$; e (9) entre $75 \%$ e $100 \%$ do total de acolhidos, por referência a unidades que não possuem crianças nessa faixa etária. Das variáveis indicadoras da configuração da equipe, duas são contínuas: (1) razão entre o total de vagas e o total de trabalhadores da unidade (coordenador, assistente social, psicólogo, cuidador e auxiliar); e (2) razão entre o total de vagas e o total de assistentes sociais e psicólogos da unidade, e duas são binárias: (3) unidades que possuem assistente social; e (4) unidades que possuem psicólogo por referência às que não possuem esses profissionais.

\footnotetext{
${ }^{17}$ Esse índice resulta do somatário de oito informações coletadas pelo Censo Suas 2013 a respeito da articulação com outros órgãos, serviços ou instituições, segundo o tipo de atividade, quais sejam: se o órgão possui dados de localização da outra unidade; recebe usuários encaminhados; encaminha usuários; acompanha os encaminhamentos; realiza reuniões periódicas; troca informações; realiza estudos de caso em conjunto; e, por fim, se desenvolve atividades com usuários em parceria.
} 
As hipóteses de análise desse terceiro modelo são: mantendo-se constante o número de acolhidos na unidade, (a) quanto maior for o número de trabalhadores na equipe, destacadamente de psicólogos e assistentes sociais, que são os profissionais encarregados de implementar a interlocução intersetorial e interinstitucional; (b) quanto menor for o percentual de pessoas com deficiência, que são as que encontram maior dificuldade de reinserção familiar; e, por fim, (c) quanto maior for o percentual de crianças com menos de cinco anos, que são as que encontram maior facilidade de reinserção, maior será a eficácia da unidade na realização da meta de provisoriedade.

Tabela 3 - Coeficientes de regressão linear do quadrado do percentual de crianças e adolescentes acolhidos por no máximo 24 meses

\begin{tabular}{|c|c|c|c|c|}
\hline & & Modelo 1 & Modelo 2 & Modelo 3 \\
\hline \multirow{4}{*}{ Região do país } & \multirow{2}{*}{ Nordeste } & $-589,28^{* *}$ & $-526,57^{* *}$ & $-396,28$ \\
\hline & & $(240,37)$ & $(243,40)$ & $(282,53)$ \\
\hline & \multirow{2}{*}{ Norte } & 140,26 & 161,45 & $-208,65$ \\
\hline & & $(362,92)$ & $(362,58)$ & $(428,51)$ \\
\hline \multirow{4}{*}{ (Ref.: Sudeste) } & \multirow{2}{*}{ Sul } & $-231,17$ & $-197,50$ & $-139,87$ \\
\hline & & $(167,45)$ & $(167,52)$ & $(177,61)$ \\
\hline & \multirow{2}{*}{ Centro-Oeste } & $464,92 *$ & $485,79 *$ & 150,81 \\
\hline & & $(264,20)$ & $(264,01)$ & $(331,64)$ \\
\hline \multirow[t]{2}{*}{ Porte do município } & \multirow{2}{*}{ Pequeno } & $-153,80$ & $-172,14$ & $-219,71$ \\
\hline & & $(164,11)$ & $(168,57)$ & $(189,34)$ \\
\hline \multirow{2}{*}{$\begin{array}{l}\text { (Ref.: grande/ } \\
\text { metrópole) }\end{array}$} & \multirow{2}{*}{ Médio } & $-14,79$ & $-44,73$ & $-90,73$ \\
\hline & & $(224,77)$ & $(225,53)$ & $(243,25)$ \\
\hline \multirow{2}{*}{ Tipo de unidade } & \multirow{2}{*}{ Casa de passagem } & $1653,11^{* * *}$ & $1673,81^{* * *}$ & $1943,22 * * *$ \\
\hline & & $(295,34)$ & $(295,89)$ & $(338,67)$ \\
\hline \multirow{3}{*}{ (Ref.: abrigo/ casa-lar) } & \multirow{2}{*}{$\begin{array}{l}\text { Residência inclusiva/ } \\
\text { Outra }\end{array}$} & $-465,02$ & $-183,78$ & $1322,60 * *$ \\
\hline & & $(520,62)$ & $(532,95)$ & $(664,78)$ \\
\hline & \multirow{2}{*}{$\begin{array}{l}\text { Não governamental } \\
\text { (sem convênio) }\end{array}$} & $-2304,75^{* * *}$ & $-2119,72 * * *$ & $-1716,54 * * *$ \\
\hline \multirow[t]{2}{*}{ Natureza da unidade } & & $(318,65)$ & $(325,63)$ & $(362,43)$ \\
\hline & \multirow{2}{*}{$\begin{array}{l}\text { Não governamental } \\
\text { (com convênio) }\end{array}$} & $-1139,50 * * *$ & $-1064,06 * * *$ & $-1050,58^{* * *}$ \\
\hline \multirow{3}{*}{$\begin{array}{l}\text { (Ref.: governamental } \\
\text { municipal) }\end{array}$} & & $(165,53)$ & $(166,89)$ & $(179,97)$ \\
\hline & \multirow{2}{*}{ Governamental estadual } & $-925,25$ & $-802,37$ & $-302,97$ \\
\hline & & $(671,55)$ & $(675,15)$ & $(777,41)$ \\
\hline \multirow{2}{*}{ Tempo de implantação } & \multirow{2}{*}{ Tempo (em meses) } & $-2,85 * * *$ & $-2,80 * * *$ & $-2,75^{* * *}$ \\
\hline & & $(0,41)$ & $(0,41)$ & $(0,44)$ \\
\hline \multirow{6}{*}{ Fiscalização } & \multirow{2}{*}{ SMAS (binária) } & & 72,02 & 89,36 \\
\hline & & & $(201,09)$ & $(215,98)$ \\
\hline & \multirow{2}{*}{ CT/CMDCA (binária) } & & $443,55^{* *}$ & $419,64 * *$ \\
\hline & & & $(186,00)$ & $(192,43)$ \\
\hline & Judiciário/ Ministério & & 293,85 & $-243,97$ \\
\hline & Público (binária) & & $(358,03)$ & $(438,50)$ \\
\hline
\end{tabular}




\begin{tabular}{|c|c|c|c|c|}
\hline & & Modelo 1 & Modelo 2 & Modelo 3 \\
\hline \multirow{2}{*}{ Índice de Articulação } & Cras, Creas, educação, & & $18,01^{* *}$ & 5,90 \\
\hline & saúde, SMAS e Judiciário & & $(8,42)$ & $(9,38)$ \\
\hline \multirow{4}{*}{$\begin{array}{l}\text { Acolhidos com } \\
\text { deficiência }\end{array}$} & Acolhidos com & & & $-27,56 * * *$ \\
\hline & deficiência (\%) & & & $(3,77)$ \\
\hline & $1 \%$ а $25 \%$ & & & 49,84 \\
\hline & $1 \%$ d $23 \%$ & & & $(191,44)$ \\
\hline$\%$ de crianças de 0 a 5 & & & & $964,79 * * *$ \\
\hline anos & $25 \%$ a $50 \%$ & & & $(199,62)$ \\
\hline \multirow{4}{*}{$\begin{array}{l}\text { (Ref.: não possui } \\
\text { criança de } 0 \text { a } 5 \text { anos) }\end{array}$} & $50 \%$ & & & $2018,70^{* * *}$ \\
\hline & ס ל וםם & & & $(317,91)$ \\
\hline & Mais de $75 \%$ & & & $2587,13 * * *$ \\
\hline & Mais de $75 \%$ & & & $(368,44)$ \\
\hline \multirow{12}{*}{ Recursos humanos } & Vagas por trabalhador & & & $-14,06$ \\
\hline & (razão) & & & $(15,23)$ \\
\hline & Vagas por assistente & & & $-13,03^{*}$ \\
\hline & social + psicólogo (razão) & & & $(7,40)$ \\
\hline & Possui assistente social & & & $-81,09$ \\
\hline & (binária) & & & $(265,89)$ \\
\hline & Possui psicólogo & & & 161,21 \\
\hline & (binária) & & & $(189,13)$ \\
\hline & Constante & $7548,87^{* * *}$ & $6290,94 * * *$ & $7047,05 * * *$ \\
\hline & & $(175,10)$ & $(486,15)$ & $(650,24)$ \\
\hline & N & 2.396 & 2.396 & 1.825 \\
\hline & $\mathrm{R}^{2}$ Ajustado & 0,09 & 0,10 & 0,17 \\
\hline
\end{tabular}

Fonte: MDSA, Censo Suas 2013. Elaboração própria.

Na Tabela 3, são apresentados os coeficientes de regressão encontrados. No primeiro e segundo modelos, verificam-se coeficientes estatisticamente significativos, positivos e negativos, respectivamente, para as unidades das regiões Centro-Oeste e Nordeste, em relação às da Sudeste, mas as diferenças perdem significância estatística no terceiro modelo, no qual são controlados o perfil dos acolhidos e a configuração da equipe técnica. Ou seja, desconsiderando essas duas dimensões (perfil e equipe), as unidades do Centro-Oeste e Nordeste apresentam, respectivamente, maior e menor eficácia na realização da meta de provisoriedade da medida de acolhimento institucional, em relação às do Sudeste.

As variáveis relativas à estrutura de provimento (tempo de implantação, modalidade do acolhimento e natureza da unidade) apresentam coeficientes 
estatisticamente significativos nos três modelos. Interpretando o resultado por meio da aplicação da raiz quadrada do coeficiente de regressão ${ }^{18}$, verifica-se, no que se refere ao tempo de implantação, que quanto mais nova é a unidade, maior é sua eficácia: no terceiro modelo, a diminuição de um mês nesse tempo está associada a um aumento médio de 1,66\% no percentual de acolhidos há menos de dois anos. Ou seja, como esperado, as unidades implantadas após o surgimento do Suas e especialmente depois da aprovação da regulamentação do ECA são mais eficazes que as implantadas antes desses eventos.

No que se refere à modalidade do acolhimento, também conforme esperado, as casas de passagem são mais eficazes que os abrigos institucionais e casas lares: no terceiro modelo, elas possuem a mais $44,08 \%$ de pessoas acolhidas há menos de dois anos. Esse resultado não surpreende e era esperado, dado que o acolhimento em casas de passagem deve ser provisório. O resultado encontrado para as residências inclusivas, por outro lado, é de certa forma surpreendente, embora compatível com o esperado: quando se controlam os efeitos da configuração da equipe técnica e do perfil dos acolhidos, elas são mais eficazes que os abrigos e as casas lares: possuem a mais $36,37 \%$ de pessoas acolhidas há menos de dois anos.

Por fim, no que se refere à natureza da unidade, verifica-se maior eficácia nas municipais em relação às não governamentais, especialmente as que não possuem convênio com o poder público: no terceiro modelo, verifica-se aumento de $41,43 \%$ e $32,41 \%$ no número de pessoas acolhidas há menos de dois anos nas municipais em relação às não governamentais sem convênio e às não governamentais com convênio, respectivamente.

Entre as variáveis indicadoras da capacidade burocrática, apresentou significância estatística, no segundo e terceiro modelos, a fiscalização do CT e CMDCA: o percentual de acolhidos há menos de dois anos aumenta em 20,49\% nas unidades que contam com essa fiscalização, por referência às que não contam. $O$ indicador de articulação/interlocução entre as unidades e os órgãos/estruturas da rede local/regional (JIJ, SMAS, Cras, Creas e estruturas de educação e saúde), contrariando a expectativa, apresenta significância estatística apenas no segundo modelo, perdendo essa qualidade com o controle do perfil dos acolhidos e da configuração da equipe técnica.

As variáveis indicadoras do perfil dos acolhidos também apresentam significância estatística e estão no sentido esperado: o aumento de $1 \%$ no número de pessoas com deficiência corresponde à redução de 5,25\% no número de pessoas acolhidas

\footnotetext{
${ }^{18}$ Para remediar certa assimetria da distribuição da variável resposta e, portanto, atender ao pressuposto da normalidade da distribuição dos resíduos, foi aplicada uma transformação exponencial à variável dependente $\left(\mathrm{Y}^{2}\right)$. Assim, a interpretação dos coeficientes pressupõe a aplicação da operação inversa, a saber, a radiciação (V).
} 
há menos de dois anos. Já o aumento no percentual de acolhidos há menos de dois anos é correlato ao aumento no percentual de crianças com menos de dois anos de idade acolhidas na unidade: naquelas em que há mais de $75 \%$ de crianças nessa faixa, o número de acolhidos há menos de dois anos é maior em $50,86 \%$ em relação às unidades que não possuem crianças nessa faixa.

Por fim, no que se refere às variáveis indicadoras da configuração da equipe técnica, apresenta significância estatística, e também no sentido esperado, a que traz a razão entre o total de vagas da unidade e o total de assistentes sociais e psicólogos na equipe: o aumento de uma vaga para cada assistente social ou psicólogo na equipe implica redução de 3,61\% no percentual de pessoas acolhidas há menos de dois anos. Ou seja, quanto mais sobrecarregados de trabalho ficam esses dois profissionais, menor é sua capacidade de implementar as ações que promovem a reinserção das crianças e adolescentes acolhidos em suas famílias de origem ou em famílias substitutas.

\section{Conclusão}

$\mathrm{Na}$ análise aqui desenvolvida, verificou-se que, em perspectiva histórica, houve avanços significativos na atenção pública à criança e ao adolescente no Brasil, em especial nas ações destinadas àqueles em situação de risco. Foram superadas as grandes instituições de recolhimento de "menores abandonados e delinquentes", das décadas de 1930 a 1960, e de "menores em situação irregular", das décadas de 1970 a 1990. Trata-se agora de anular os aspectos negativos deixados por essa trajetória, criando as condições organizacionais para que crianças e adolescentes, incluindo os oriundos de famílias pobres, tenham acesso, com prioridade absoluta, a uma proteção estatal que Ihes assegure os direitos necessários ao seu pleno desenvolvimento, incluindo o de convivência familiar e comunitária.

O desenho do serviço de acolhimento institucional, tal como estabelecido pelo ECA e regulamentado no final da década de 2000, parece estar em perfeita consonância com esse desiderato. Junto com o fortalecimento do sistema de proteção social brasileiro, em especial nas áreas de assistência social, saúde e educação, esse desenho inegavelmente tem propiciado melhores condições de proteção da criança e do adolescente fora de abrigos. Na medida em que estes deixaram de ser a única alternativa de educação, saúde e assistência social para as famílias pobres, e que a atenção à criança e ao adolescente começou a ser priorizada por um amplo conjunto de instituições estatais e não estatais, que atuam de forma territorial e funcionalmente interdependente, verificou-se uma diminuição importante na prática de sua institucionalização nos últimos 30 anos. 
Mas os desafios que ainda se interpõem a uma proteção integral são enormes. Em primeiro lugar, o sistema de proteção social, assim como a atuação das instituições que compõem a rede de proteção ainda têm permitido que crianças e adolescentes sejam ou permaneçam separados do convívio familiar e comunitário por razões injustificáveis, como a pobreza. Em segundo lugar, o direito de crianças e adolescentes ao acolhimento institucional nas situações de risco ainda não está garantido em todo o território nacional nem nas condições preconizadas pela legislação em vigor: nas regiões Sudeste e Sul e nas grandes cidades, a possibilidade de proteção é bem maior que nas regiões Nordeste, Norte e Centro-Oeste e nas cidades de pequeno e médio portes. Além disso, se não se consideram a capacidade e configuração das equipes técnicas e o perfil dos acolhidos, há chances significativamente menores, em termos estatísticos, de uma criança ou adolescente deixar a unidade no período preconizado pelo ECA na Região Nordeste, relativamente às outras regiões do país, especialmente a Centro-Oeste.

Essas chances estão também relacionadas com a capacidade das burocracias envolvidas na gestão do serviço, nos termos de Gomide e Pires (2014). A esse respeito, merece menção a importância da fiscalização dos CT e CMDCA sobre as unidades, que se mostrou relacionada, de forma estatisticamente significativa, com a eficácia destas na realização da meta de provisoriedade da medida de acolhimento. Cabe lembrar que essa fiscalização tem a ver com a autonomia dessas instâncias de participação social na implementação da política, o que se relaciona, de acordo com Gomide e Pires (2014), com a atuação das burocracias situadas no Poder Executivo. Corroboram também o argumento desses autores a relação, estatisticamente significativa, entre a provisoriedade do acolhimento e a interlocução que se dá entre as unidades e a rede de instituições e estruturas de políticas setoriais durante a prestação do serviço (apesar de essa relação ter perdido significância estatística no terceiro modelo, assim como a relação, também estatisticamente significativa, entre a provisoriedade do acolhimento e a data de implantação da unidade e o perfil das equipes de trabalho). Considerando que o arranjo instituído pelo ECA foi regulamentado apenas em 2009, e que não houve iniciativas nacionalmente coordenadas de capacitação das burocracias de unidades criadas sob a vigência de normatizações anteriores, não surpreende que nelas o desempenho na reinserção familiar das crianças e adolescentes seja pior, assim como não surpreende que a sobrecarga de trabalho dos profissionais responsáveis por desenvolver as ações que promovem a reinserção familiar - psicólogos e assistentes sociais - resulte em aumento no tempo de acolhimento.

Por fim, merece menção e, mais importante, requer pesquisas adicionais, o fato de as unidades não governamentais, mesmo as conveniadas, serem significativamente, em termos estatísticos, menos eficazes que as governamentais 
municipais. A diferença resiste mesmo quando mantidas sobre controle variáveis relativas ao contexto e à estrutura de provimento do serviço, e aquelas indicadoras da capacidade burocrática, do perfil dos acolhidos e da configuração das equipes técnicas. $O$ argumento de que essas unidades estão mais distanciadas das burocracias instaladas na estrutura direta (da assistência social), na qual supostamente se acumula a expertise necessária ao bom desempenho da gestão, é, apesar de plausível, demasiado genérico. O que as burocracias das unidades não governamentais fazem ou deixam de fazer que as tornam menos eficazes na reinserção familiar das crianças e adolescentes? A resposta a essa questão é uma das que devem orientar os gestores da área nas decisões relativas à ampliação e desconcentração da oferta do serviço: por meio da implantação de novas unidades ou abertura de novas vagas na estrutura direta dos governos municipais ou estaduais ou pelo conveniamento com entidades privadas de assistência social.

\section{Referências bibliográficas}

ASSIS, S.; FARIAS, L. (Orgs.).Levantamento nacional de crianças e adolescentes em serviço de acolhimento. São Paulo: Hucitec Editora, 2013.

ARREtCHE, M. Políticas sociais no Brasil: descentralização em um Estado federativo. Revista Brasileira de Ciências Sociais, n. 40, p. 111-141, 1999.

BICHIR, R. Capacidades estatais para a implementação de programas de transferência de renda: os casos de Brasil, Argentina e África do Sul. Texto para Discussão no 2032. Brasília: Ipea, 2015.

BRASIL. Lei no 8.069, de 13 de julho 1990. Dispõe sobre o Estatuto da Criança e do Adolescente e dá outras providências. Disponível em: <http://www.planalto. gov. br/ccivil_03/LEIS/L8069.htm\#art267>. Acesso em: 20/01/2013.

. Lei no 6.697, de 10 de outubro de 1979. Institui o Código de Menores. Disponível em <http://www.planalto.gov.br/ccivil_03/leis/1970-1979/L6697.htm>. Acesso em: 20/01/2013.

Lei no 8.742, de 7 de dezembro de 1993. Dispõe sobre a organização da Assistência Social e dá outras providências. Disponível em: <http://www.planalto. gov.br/ccivil_03/leis/L8742.htm>. Acesso em: 15/08/2012.

BRASIL. Presidência da República. Decreto no 17.943-A, de 12 de dezembro de 1927. Consolida as leis de assistencia e protecção a menores. Disponível em: <http:// www.planalto.gov.br/ccivil_03/decreto/1910-1929/D17943A.htm>. Acesso em: 20/01/2013.

Bronzo, C. Exclusão: delimitação conceitual e os desafios para a mensuração. Pensar BH/Política Social, n. 25, p. 12-19, 2010.

CARDoso JR, J.; JACcoud, L. Políticas sociais no Brasil: organização, abrangência e tensões da ação estatal. In: JACcouD, L. (Org.). Questão social e políticas sociais no Brasil contemporâneo. Brasília: Ipea, 2005, p. 181-260. 
Cavalcante, P.; LotTA, G. (Orgs.). Burocracia de médio escalão: perfil, trajetória e atuação. Brasília: Enap, 2015.

CASTELLS, M. Hacia el Estado red? Globalización económica e instituciones políticas en la era de la información. In: SEMINÁRIO INTERNACIONAL SOCIEDADE E A REFORMA Do ESTADO, 1998, São Paulo.

Conselho nacional dos Direitos da Criança e do Adolescente (Conanda); Conselho nacional de Assistência Social (CNAS). Resolução Conjunta no 1, de 18 de junho de 2009. Aprova o documento Orientações Técnicas: Serviços de Acolhimento para Crianças e Adolescentes.

CONSELHo NACIONAL DE ASSIStÊnCIA SOCIAL (CNAS). Resolução 33, de 12 de dezembro de 2012. Aprova a Norma Operacional Básica do Sistema Único de Assistência Social - NOB/Suas.

DAGNINO, E. Sociedade civil, participação e cidadania: de que estamos falando? In: Mato, D. (Coord.). Políticas de ciudadanía y sociedad civil en tiempos de globalización. Caracas: Faces, Universidad Central de Venezuela, 2004.

DRAIBE, S. O sistema brasileiro de proteção social: o legado desenvolvimentista e a agenda recente de reformas. Caderno de Pesquisa no 32. São Paulo: Unicamp/ NEPP, 1998.

GoMIDE, A.; PIRES, R. Capacidades estatais e democracia: a abordagem dos arranjos institucionais para análise de políticas públicas. In: GoMIDE, A.; PIRES, R. (Eds.). Capacidades estatais e democracia: arranjos institucionais de políticas públicas. Brasília: Ipea, 2014. p. 15-28.

JUNQUEIRA, L. Gestão intersetorial das políticas sociais e o terceiro setor. Saúde e Sociedade, v. 13, n. 1, p. 25-36, 2004.

LIPSKY, M. Street level bureaucracy. Publications of Russell Sage Foundation, 1980.

MedeIRos, M. A trajetória do Welfare State no Brasil: papel redistributivo das políticas sociais dos anos 1930 aos anos 1990. Texto para Discussão no 852. Brasília: Ipea, 2001.

MenicucCI, T. Intersetorialidade, o desafio atual para as políticas sociais. Pensar BH / Política Social, n. 3, p. 10-13, 2002.

Ministerio do Desenvolvimento Social e Combate À Fome (MDS) / Conselho NACIONAL DE ASSISTÊNCIA SOCIAL (CNAS). Resolução no 109, de 11 de novembro de 2009. Aprova a Tipificação Nacional de Serviços Socioassistenciais. Brasília, 2009.

RızzıNı, I.; RızzıNı, I. A institucionalização de crianças no Brasil: percurso histórico e desafios do presente. São Paulo: Edições Loyola, 2004.

SECCHI, L. Modelos organizacionais e reformas da administração pública. Revista de Administração Pública - RAP, v. 43, n. 2, p. 347-369, 2009.

SERRA, A. La gestión transversal: expectativas y resultados. Revista del CLAD Reforma y Democracia, n. 32, 2005. Disponível em: <http://siare.clad.org/revistas/0049633. pdf>. Acesso em: 15/04/2015. 
Silva, F.; Jaccoud, L.; Beghin, N. Políticas sociais no Brasil: participação social, conselhos e parcerias. In: JACCOUD, L. (Org.). Questão social e políticas sociais no Brasil contemporâneo. Brasília: Ipea, 2005. p. 373- 407.

TEIXEIRA, S. O desafio da gestão das redes de políticas. In: CONGRESSO INTERNACIONAL del Clad SOBRE LA Reforma del ESTAdo y DE LA AdMinistración PúbliCA, 7., 2002, Lisboa, Portugal. Disponível em: <http://unpan1.un.org/intradoc/groups/public/ documents/CLAD/clad0043204.pdf>. Acesso em: 29/04/2015.

\section{Geralda Luiza Miranda}

Possui doutorado em Ciência Política pela Universidade Federal de Minas Gerais (UFMG). Atualmente é professora adjunta na Faculdade de Filosofia e Ciências Humanas, na UFMG. Contato: geraldaluizam@hotmail.com

\section{Valéria Cristina de Oliveira}

Possui doutorado em Sociologia pela Universidade Federal de Minas Gerais (UFMG). Atualmente é professora adjunta na Faculdade de Educação da UFMG. Contato: valcrisoli@gmail.com 


\section{Apêndice}

Quadro 1 - Descrição das variáveis resposta e explicativas do modelo de regressão linear

\begin{tabular}{|c|c|c|c|c|c|c|}
\hline \multicolumn{2}{|c|}{ Variável resposta } & $\mathbf{N}$ & Média/\%* & $\begin{array}{l}\text { Desvio } \\
\text { padrão }\end{array}$ & Mín. & Máx. \\
\hline \multicolumn{2}{|c|}{$\begin{array}{l}\text { Crianças e adolescentes acolhidos por até } \\
24 \text { meses (\%) }\end{array}$} & 2.397 & $74,25 \%$ & $29,07 \%$ & 0 & 100 \\
\hline \multicolumn{2}{|c|}{ Variáveis explicativas } & $\mathbf{N}$ & Média/\%* & $\begin{array}{l}\text { Desvio } \\
\text { padrão }\end{array}$ & Mín. & Máx. \\
\hline \multirow{5}{*}{$\begin{array}{l}\text { Região do } \\
\text { país }\end{array}$} & Nordeste & 2.464 & $11,04 \%$ & 0,3134 & 0 & 1 \\
\hline & Norte & 2.464 & $4,38 \%$ & 0,2048 & 0 & 1 \\
\hline & Sul & 2.464 & $27,44 \%$ & 0,4463 & 0 & 1 \\
\hline & Centro-Oeste & 2.464 & $8,20 \%$ & 0,2744 & 0 & 1 \\
\hline & Sudeste & 2.464 & $48,94 \%$ & 0,5000 & 0 & 1 \\
\hline \multirow{3}{*}{$\begin{array}{l}\text { Porte do } \\
\text { município }\end{array}$} & Pequeno (I ou II) & 2.464 & $36,36 \%$ & 0,4811 & 0 & 1 \\
\hline & Médio & 2.464 & $12,22 \%$ & 0,3275 & 0 & 1 \\
\hline & Grande & 2.464 & $51,42 \%$ & 0,4999 & 0 & 1 \\
\hline \multirow{3}{*}{$\begin{array}{l}\text { Tipo da } \\
\text { unidade }\end{array}$} & Casa de passagem & 2.464 & $6,57 \%$ & 0,2479 & 0 & 1 \\
\hline & Residência inclusiva/Outra & 2.464 & $1,95 \%$ & 0,1382 & 0 & 1 \\
\hline & Abrigo / Casa-lar & 2.464 & $91,48 \%$ & 0,2793 & 0 & 1 \\
\hline \multirow{4}{*}{$\begin{array}{l}\text { Natureza da } \\
\text { unidade }\end{array}$} & $\begin{array}{l}\text { Não governamental (sem } \\
\text { convênio) }\end{array}$ & 2.464 & $5,93 \%$ & 0,2361 & 0 & 1 \\
\hline & $\begin{array}{l}\text { Não governamental (com } \\
\text { convênio) }\end{array}$ & 2.464 & $46,35 \%$ & 0,4988 & 0 & 1 \\
\hline & Governamental estadual & 2.464 & $1,14 \%$ & 0,1060 & 0 & 1 \\
\hline & Governamental municipal & 2.464 & $46,59 \%$ & 0,4989 & 0 & 1 \\
\hline \multicolumn{2}{|c|}{ Tempo de implantação (em meses) } & 2.463 & 158,5871 & 176,2050 & 0 & 1563 \\
\hline \multirow{3}{*}{ Fiscalização } & Fiscalização da SMAS & 2.464 & $84,33 \%$ & 0,3635 & 0 & 1 \\
\hline & $\mathrm{CT} / \mathrm{CMDCA}$ & 2.464 & $81,45 \%$ & 0,3888 & 0 & 1 \\
\hline & Judiciário/ Ministério Público & 2.464 & $95,45 \%$ & 0,2083 & 0 & 1 \\
\hline Articulação & $\begin{array}{l}\text { Índice de articulação CRAS, } \\
\text { CREAS, educação, saúde, } \\
\text { SMAS e Judiciário }\end{array}$ & 2.464 & 26,8304 & 8,7143 & 0 & 46 \\
\hline Deficiência & Acolhidos com deficiência (\%) & 2.397 & $9,8 \%$ & 21,1747 & 0 & 200 \\
\hline \multirow{5}{*}{$\begin{array}{l}\text { \% de } \\
\text { acolhidos } \\
\text { com menos } \\
\text { de } 6 \text { anos de } \\
\text { idade }\end{array}$} & Nenhum & 2.397 & $33,6 \%$ & 0,4724 & 0 & 1 \\
\hline & $0,1 \%$ a $25 \%$ & 2.397 & $28,2 \%$ & 0,4499 & 0 & 1 \\
\hline & $25 \%$ a $50 \%$ & 2.397 & $25,5 \%$ & 0,4361 & 0 & 1 \\
\hline & $50 \%$ a $75 \%$ & 2.397 & $7,7 \%$ & 0,2669 & 0 & 1 \\
\hline & Mais de $75 \%$ & 2.397 & $5,0 \%$ & 0,2181 & 0 & 1 \\
\hline
\end{tabular}




\begin{tabular}{|c|c|c|c|c|c|c|}
\hline \multicolumn{2}{|c|}{ Variável resposta } & $\mathbf{N}$ & Média/\%* & $\begin{array}{l}\text { Desvio } \\
\text { padrão }\end{array}$ & Mín. & Máx. \\
\hline \multicolumn{2}{|c|}{$\begin{array}{l}\text { Crianças e adolescentes acolhidos por até } \\
24 \text { meses (\%) }\end{array}$} & 2.397 & $74,25 \%$ & $29,07 \%$ & 0 & 100 \\
\hline \multicolumn{2}{|c|}{ Variáveis explicativas } & $\mathbf{N}$ & Média/\%* & $\begin{array}{l}\text { Desvio } \\
\text { padrão }\end{array}$ & Mín. & Máx. \\
\hline \multirow{4}{*}{$\begin{array}{l}\text { Recursos } \\
\text { humanos }\end{array}$} & Vagas por trabalhador & 2.464 & 3,6664 & 7,8353 & 0,2 & 120,0 \\
\hline & $\begin{array}{l}\text { Vagas por assistente social + } \\
\text { psicólogo }\end{array}$ & 1.864 & 11,9289 & 13,5686 & 1,2 & 220,0 \\
\hline & Possui assistente social & 2.464 & 0,6802 & 0,4665 & 0 & 1 \\
\hline & Possui psicólogo & 2.464 & 0,5657 & 0,4958 & 0 & 1 \\
\hline
\end{tabular}

Fonte: MDSA, Censo Suas 2013. Elaboração própria. 
RSP 